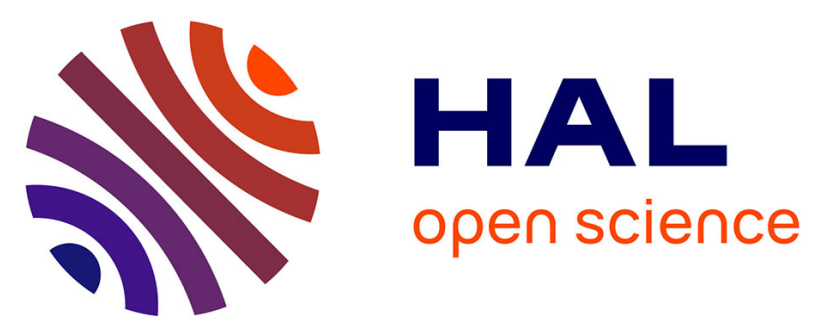

\title{
Design and Implementation of a Prototype for Information Exchange in Digital Manufacturing Processes in Aerospace Industry
}

\author{
Andrés Padillo, Jesús Racero, Manuel Oliva, Fernando Mas
}

\section{To cite this version:}

Andrés Padillo, Jesús Racero, Manuel Oliva, Fernando Mas. Design and Implementation of a Prototype for Information Exchange in Digital Manufacturing Processes in Aerospace Industry. 14th IFIP International Conference on Product Lifecycle Management (PLM), Jul 2017, Seville, Spain. pp.590-600, 10.1007/978-3-319-72905-3_52 . hal-01764192

\author{
HAL Id: hal-01764192 \\ https://hal.inria.fr/hal-01764192
}

Submitted on 11 Apr 2018

HAL is a multi-disciplinary open access archive for the deposit and dissemination of scientific research documents, whether they are published or not. The documents may come from teaching and research institutions in France or abroad, or from public or private research centers.
L'archive ouverte pluridisciplinaire HAL, est destinée au dépôt et à la diffusion de documents scientifiques de niveau recherche, publiés ou non, émanant des établissements d'enseignement et de recherche français ou étrangers, des laboratoires publics ou privés. 


\title{
Design and implementation of a prototype for information exchange in digital manufacturing processes in aerospace industry
}

\author{
Andrés Padillo ${ }^{1}$, Jesús Racero ${ }^{1}$, Manuel Oliva ${ }^{2}$, Fernando Mas $^{2}$ \\ ${ }^{1}$ Fundación para la investigación de las tecnologías de la información en Andalucía \\ ${ }^{2}$ Airbus \\ andres.padillo@p2lm.org,jrm@us.es, manuel.oliva@airbus.com, fernando.mas@airbus.com
}

\begin{abstract}
Aerospace companies have a wide range of information systems with different functionalities that are used along the aircraft lifecycle; this causes problems in terms of integration, information exchange and long term archiving of data. Ongoing standardization efforts, mainly under the standard ISO 10303 and the LOTAR initiative are addressing such problems. This communication shows a starting work dealing with the exchange of aircraft industrialization information. It proposes a simplified data structure to illustrate and validate an exchange approach based on combining ISO 10303 EXPRESS-G, UML class diagram and ISO 10303 EXPRESS-I. The PLM software Aras Innovator was used to make the implementation and validate the approach.
\end{abstract}

Keywords: Interoperability, iDMU, ISO 10303, STEP, Express-G, UML

\section{Introduction}

Since the beginnings of the 90 s, the development of an aircraft program is performed using methods based on concurrent engineering, with multidisciplinary work teams, and with the support of PDM/PLM/CAX (Product Data Management/Product Lifecycle Management/Computed Aided apps) [1][2][3][4].

The life cycle extension of an aircraft has a relevant impact on the volume of data generated, its management, as well as its long-term storage and access [4]. The integration of product data and industrialization data leads to an evolution from a digital mock-up (DMU) based on product data to an industrial digital mock-up (iDMU), which integrates both [3]. When limiting the industrialization to the product assembly, the industrial context contains the entire product structure, the assembly processes and the assembly resources, all of them integrated within a virtual definition of an assembly process structure. In the aerospace sector, the creation of the iDMU involves several organizations (OEM, suppliers), lasts several years and evolves over time [3]. This situation makes particularly relevant the exchange of information and its longterm storage.

There is extensive literature addressing the issues of integration and interoperability of information systems, and the standardization of information exchange as a way 
to address those issues [5-8]. The different information systems, used by aerospace companies over time, leads to a dependency situation where the aerospace company owns the data and information IP (Intellectual Property), but does not have full control of access to such intellectual property (knowledge) throughout the entire aircraft life-cycle [8].

When looking at the current trends in collaborative engineering practices, the implementation of Model-based systems engineering (MBSE) practices, where domain models are used as means of information exchange, prompts a higher relevance of the interoperability issues. Facilitate the exchange of information independently of the software systems acquires greater relevance. Eventually, the aim is the complete implementation of the collaborative engineering based on models, from the early design stages to the operation services. The key element to facilitate such a MBSE practices is ontology [9]. Therefore, the development of ontologies becomes the fundamental support element for the interoperability of software systems used in design, manufacture, certification, operation, support services and disposal of the aircraft.

Focused on the assembly processes, this work shows a starting approach to facilitate the information exchange within an iDMU context. The method used was structure into three main steps:

- Definition of a data model to support the iDMU concept. The developed data model is a simplified attempt to integrate the three main structures that comprises an iDMU: product, processes and resources. The data model was created using UML (Unified Modeling Language).

- To follow the STEP methodology, the data model must be specified in the EXPRESS language. Current UML based modeling and design tools, such as Enterprise Architect (EA), allow creating templates to transform existing UML class diagrams into different notations. This feature was used to create an EXPRESS-G schema from the proposed iDMU UML data model. EA macros were also developed to populate and validate the data model by creating instances and their persistent storage using EXPRESS-I notation.

- Implementation of the proposed iDMU data model in ARAS Innovator, a commercial open-access PLM software.

The paper is structured into several parts. Section 2 provides a description of the iDMU concept. Section 3 provides a brief description of the standard for product data exchange ISO 10303 (STEP) and the graphical modeling notation EXPRESS-G. Section 4 shows the proposed simplified data model and its implementation in a first prototype. Section 5 shows the results obtained. Finally, the conclusions of this work are presented.

\section{Components of the industrial Digital Mock-up (iDMU)}

The iDMU concept is an approach defined in Airbus to facilitate the integration of information along the collaborative development of an aircraft [3]. 


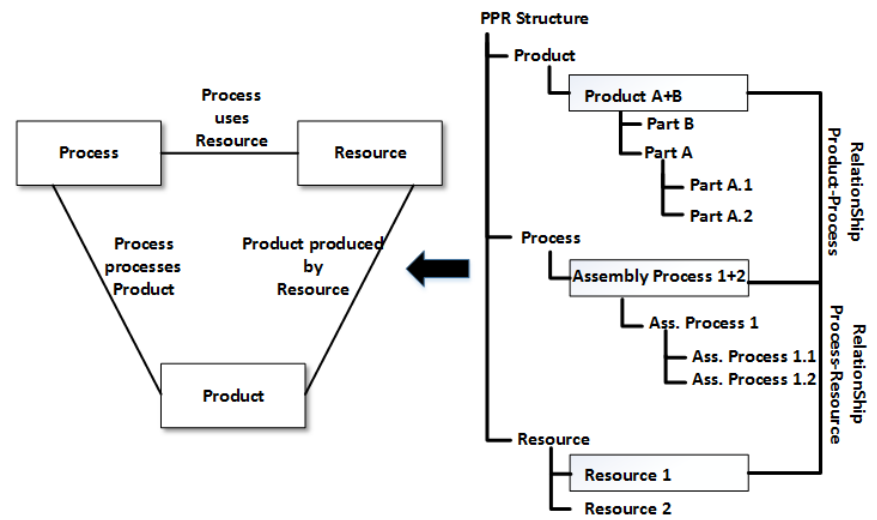

Fig. 1. Example of Product, Process and Resource relationship structure.

An iDMU aims integrating all the industrialization information, in particular, Product, Processes and Resources to model a virtual assembly line [3, 10].

The model establishes the links and assignments between the different elements that compose it. That is, between Assembly Processes, Products and Resources. These relationships and assignments are established with the aim of designing and validating an industrialization context. Fig. 1 shows a generic example.

\section{Information Exchange: ISO 10303 STEP}

STEP, the Standard for the Exchange of Product Model Data, is a comprehensive ISO standard (ISO 10303) that describes how to represent and exchange digital product information. STEP is the main reference in the neutral specification of product data for the integration and interoperability between computer applications over the product life cycle [11-13].

EXPRESS is a standard data modeling language defined in the part ISO 10303-11. A data model can be defined in two ways, textually (EXPRESS) and graphically (EXPRESS-G). EXPRESS-I can be used to create instances of the entities defined in the model. Although the persistent storage of instances is specified in the EXPRESS file format specified in the ISO 10303-21 [13].

EXPRESS-G is a useful notation, for visual interpretation of the static part of a data model, type of entities and attributes, relationships and cardinality. The capabilities of EXPRESS-G can be easily map into UML Class diagrams or vice versa [14].

According to the STEP standard, the specification of the information or data exchange within a specific context requires the definition of an Application Protocol (AP). Three models compose an AP: Application Activity Model (AAM), Application Reference Model (ARM) and Application Interpreted Model (AIM) [12].

- The AAM model contains a description of the context in terms of functions and processes involved in the industrial application. This model is basically document- 
ed using the IDEF0 technique, is an informative part of the AP and is not a standard part [12].

- The ARM model contains a specification of the information/data of the application context. It is also an informative part of the AP and is not a standard part [12].

- The AIM model contains the interpretation and mapping between the concepts of the ARM model and the concepts defined by the STEP standard itself in the different resource parts. This model is documented in EXPRESS and is the standard part of the AP [12].

STEP APs cover a wide variety of contexts, some of them are specific to some industrial sectors (e.g. AP 214 is focused on Automotive Industry), but other ones are generic (e.g. AP203 applies to mechanical 3D CAD in general). Several APs are relevant to the aerospace sector, for instance, for $3 \mathrm{D} \mathrm{CAD}$ with product manufacturing information (AP203 and AP214), for engineering analysis and simulation (AP209 and AP242).

The application of STEP APs goes beyond data exchange and has become a key element in the aerospace long term archiving of data. The project LOTAR (Long Term Archiving and Retrieval), focused on product and technical documentation in digital format, is a project initially promoted by the ASD (AeroSpace and Defense Industry Association of Europe), and whose outcomes are published as European standards by the European Committee for Normalization (CEN). Whenever possible, the LOTAR standards are based on STEP, and the LOTAR WGs participates actively in the development of STEP [15-16].

\section{Proposed iDMU data model: structure and implementation}

\subsection{Structure of the proposed iDMU data model}

The Unified Modeling Language (UML) is especially suited for the modelling of complex, distributed and concurrent systems [17-18].

Class diagrams are a type of static structure diagram where the entities are represented and defined in the data model. A class is formed by attributes and operations, and may have associations with other classes. By means of a compiler or code generation utility, it is possible to generate source code in an object oriented programing language from a class diagram. Although, there are a few compilers to generate source code from an STEP EXPRESS schema, an interesting alternative is to map an EXPRESS-G schema into an UML class diagram, and then compile such a class diagram to generate source code in an object oriented programming language [17-18]. This approach was adopted in this work.

When considering a possible structure of an iDMU data model, the work Mas [10] is a reference to be considered. Taking that work as basis, an iDMU simplified model was created to demonstrate and validate a possible industrialization data exchange between software systems. Fig. 2 shows the simplified model used in this work. 


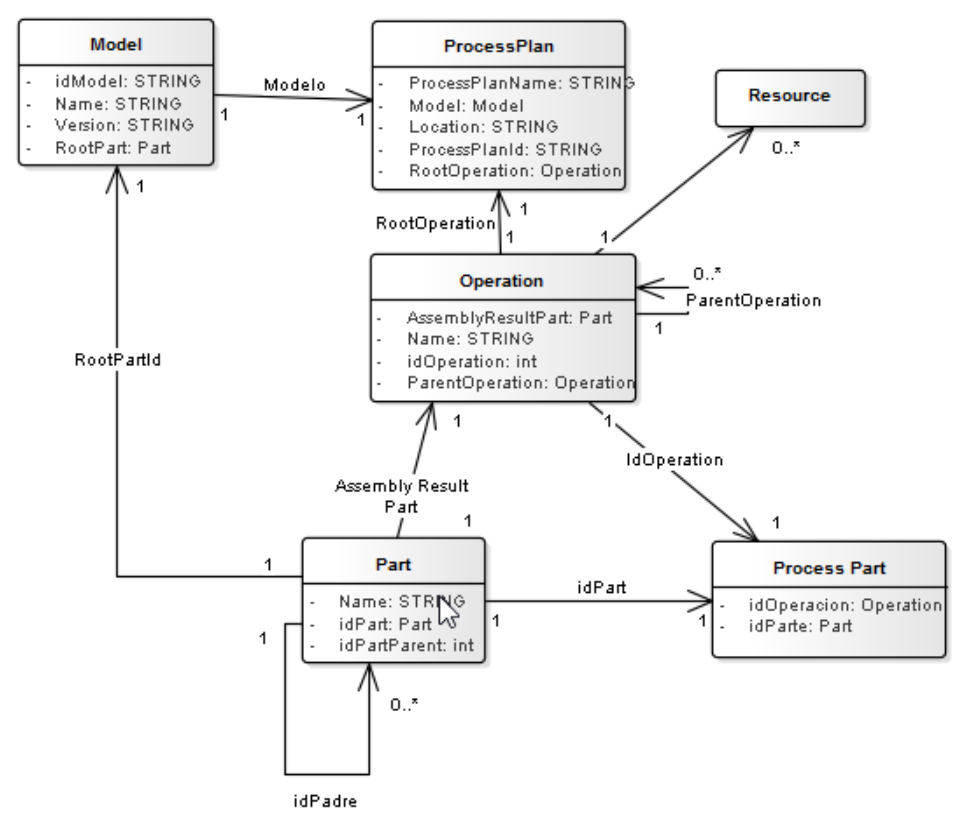

Fig. 2. Simplified iDMU data model

The following entities or classes represent the different elements of the iDMU structure:

- Process Plan: represents the root node in a manufacturing structure, responsible for the description and sequencing of operations necessary for the transformation of different parts into a finished product.

- Model: represents an entity to specify the graphical representation of a specific product.

- Operation: represents an action of transformation collected in a process plan.

- Part: represents the lower level unit that results from decomposing a product.

- Process Part: represents the entity resulting from the transformation of different parts collected in a process plan.

- Resource: represents the sources or supplies used in any transformation action included in a Process Plan.

One of the main features of existing tools in relation to diagrams based on UML notation is the ability to generate source code in an explicit object oriented programming language. Among UML-based code generation tools Enterprise Architect allows a complete parameterization offering the opportunity to analyze the feasibility of developing templates for the generation of "Schemas" using EXPRESS-G based on UML class diagrams. In addition to a macro language for the generation of code in EXPRESS-I format and transformation code in different languages based on the schema. 


\subsection{Implementation of the iDMU data model.}

The functional model has been structured in two parts. The first one defines the iDMU data model structure using a class diagram (Fig.3 iDMU Definition). The second one, the code generation of data model in EXPRESS-I as well as the transformation functions for systems and whose interoperability to be implemented.

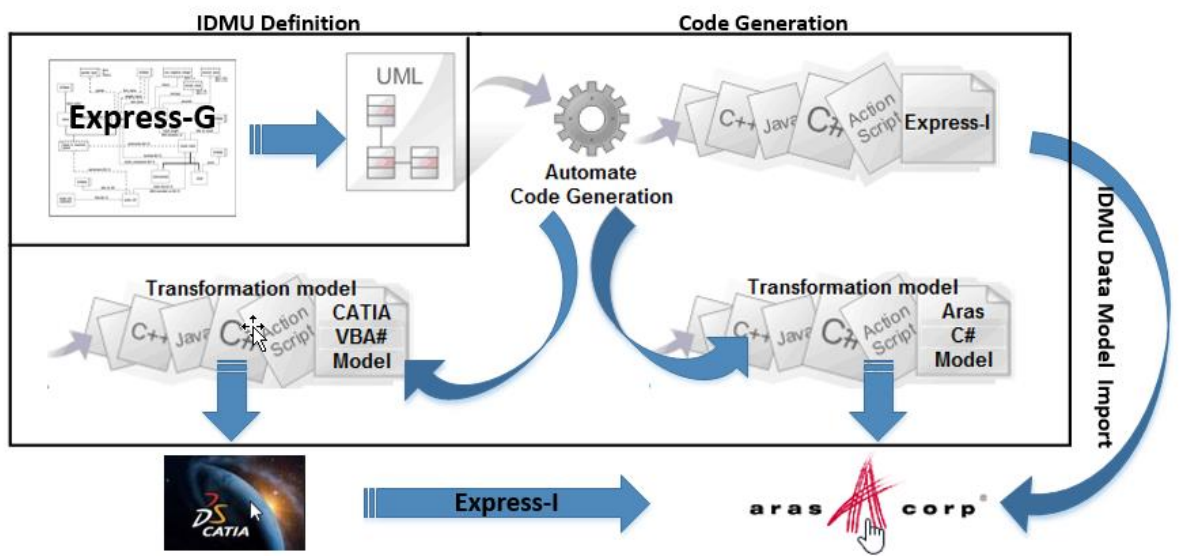

Fig. 3. Functional model

This paper reflects the feasibility and interoperability between PLM systems. Throught out an EXPRESS-I file to implement it in PLM software ARAS INNOVATOR [15] to allow importing the iDMU data model structure from CATIA/DELMIA V5.

DELMIA's V5 DPM Assembly (commercial software, which integrates CATIA design with assembly process definition) is a CAM developed by Dassault Systèmes to optimize process engineering and the assembly manufacturing, enabling to users simulate and validate a manufacturing process plan..

ARAS Innovator is an Open Source software that offers PLM and PDM solution integration services on a single platform, and allows the user to manage the entire product life cycle. The programming code is open so the software can be distributed, developed and modified freely without restrictions of licenses.

To achieve flexibility, ARAS has focused on the creation of a run-time web application that runs a set of services coupled, that is, forming a service-oriented architecture (SOA).

The development of applications associated with the ARAS Innovator system can be done either from the system or from the Visual Studio .NET programming environment and they can be executed in the client or server environment. This work has been developed in applications server because imply a customization of the system with new types of data.

To demonstrate the interoperability study, it will be necessary to update ARAS for reading based on ISO 10303 through a $\mathrm{C}$ \# reconciliation interface between the Express schema and the data import from the iDMU to ARAS. It will read the schema file with the entities, relations and attributes besides creating the own data types in 
ARAS, in order to introduce the product data and the scheme both in ARAS and define automatically an assembly structure based on the iDMU. (Figure 3)

\section{$5 \quad$ Results}

The proposed methodology has been implemented and applied for a basic iDMU structure. The objective of this test is to define the EXPRESS-G structure using a class diagram and generate the code of the iDMU assembly process in EXPRESS-I format, as well as transformation models in VBA (CATIA/DELMIA) and C\# (ARAS Innovator).

For this work and its subsequent use at educational level has opted for a LEGO model, the 6745-H deriving from the program 6745 (Figure 4).

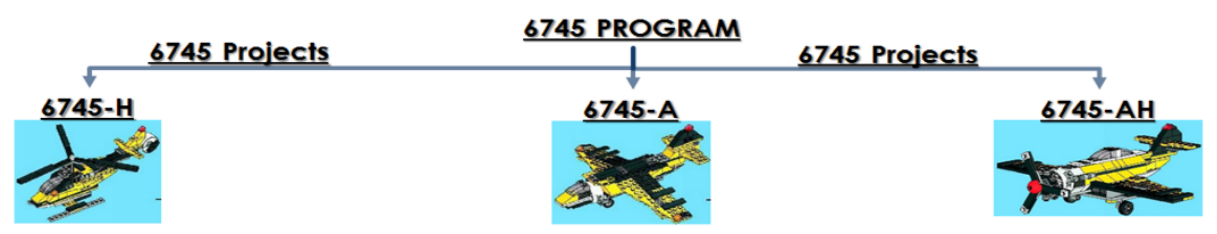

Fig. 4. Define program and projects

The helicopter has a total of 247 pieces and the purpose of this test is to define the assembly process in format.

The helicopter has a total of 247 pieces and the purpose of this test is to define the assembly process in format.

The steps for designing the manufacturing structure model have been:

- Definition of EBOM structure (Engineering Bill Of Material), to describe the groupings and different parts of the model with the aim of making a more coherent the manufacturing process.

- Definition of the MBOM structure (Manufacturing Bill Of Material), to describe how the product is manufactured and to facilitate a rapid relationship between the manufacturing process and the assembly product obtained.

The data model defined for transformations between systems includes entities and attributes, schemas, and relationships between entities (Class diagram and Activity diagram). This data model is the base for generation code in the transformation models, because generates the source code automatically for the import and generation of data types (Figure 5). 


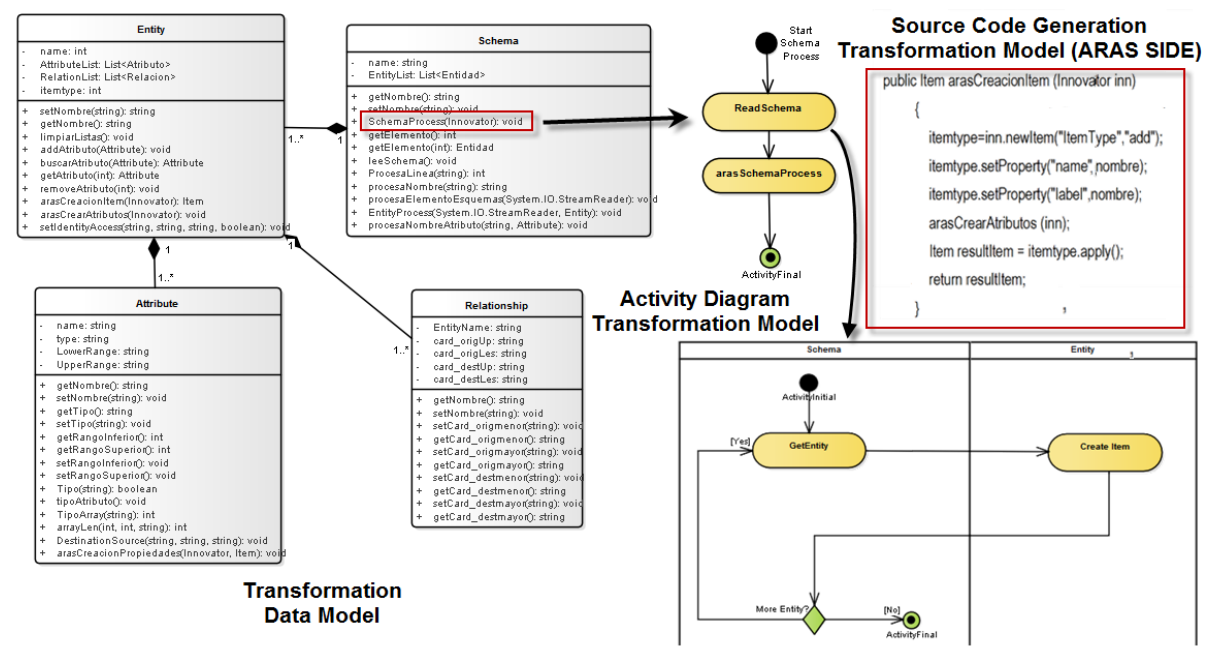

Fig. 5. Definition of Transformation Model structure for code generation (from UML to EXPRESS)

The EXPRESS-I generated code for schema is show below, the file begins with the header where it is provided information of the characteristics of the data.

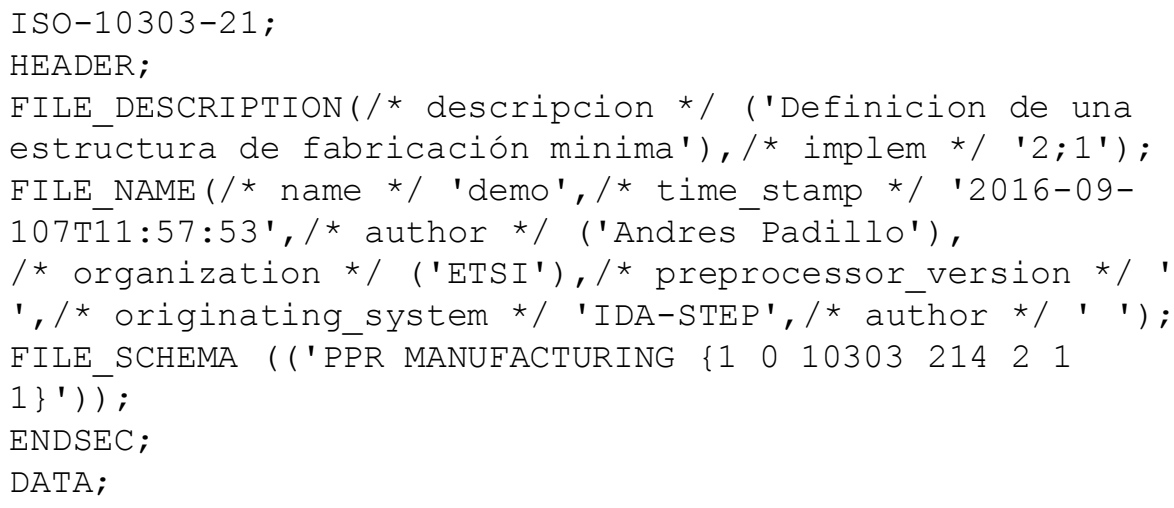

After the header section the data is displayed. Each data is identified by a number on the left and preceded by a \#.This identification is fundamental to reference information between entities. The first four data lines describe the process plan, the model and the parts / components / subproducts of the manufacturing structure. the process plan $6745 \mathrm{H}-\mathrm{PPR}$ has associated a model whose definition is in \# 11 . The model has a part or final product whose definition is in \# 12.It is important to emphasize that the parts do not have associated subcomponents, but each part specifies the part to which it is united to form a superior set, except the first one that does not have father (Specified with a $\$$ ). 


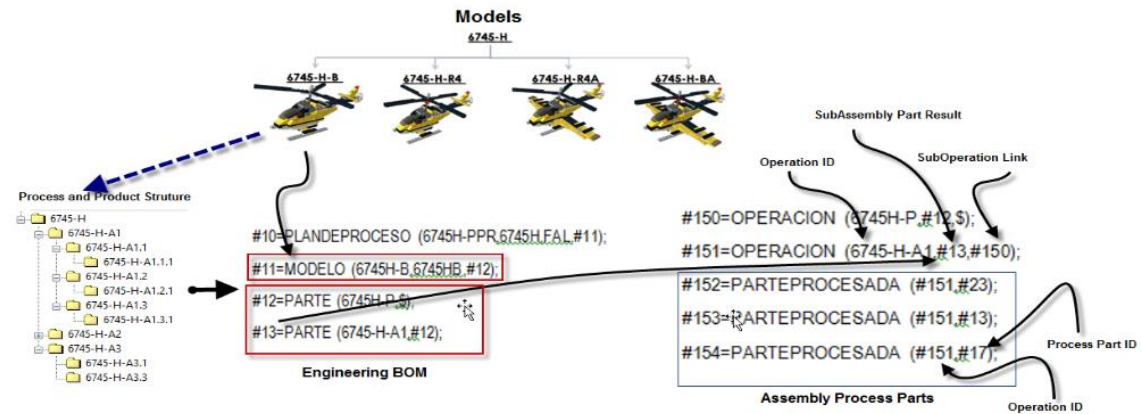

Fig. 6. Interoperability data between software platforms (Express Based)

The operation entity is defined by name, the part / product or resulting component or result of the operation and the parent operation that needs this operation to be performed. For example, reference \# 150 defines the root operation used to obtain the part referenced by \# 12 (Helicopter). Instead the operation referenced as \# 151 generates the component referenced by \# 13 and is performed before the parent operation \# 150. Finally, each operation has associated a set of parts to be processed or assembled, in this example the operation \# 151 uses or processes parts \# 23, \# 13, \#17 (Figure 6,7$)$.

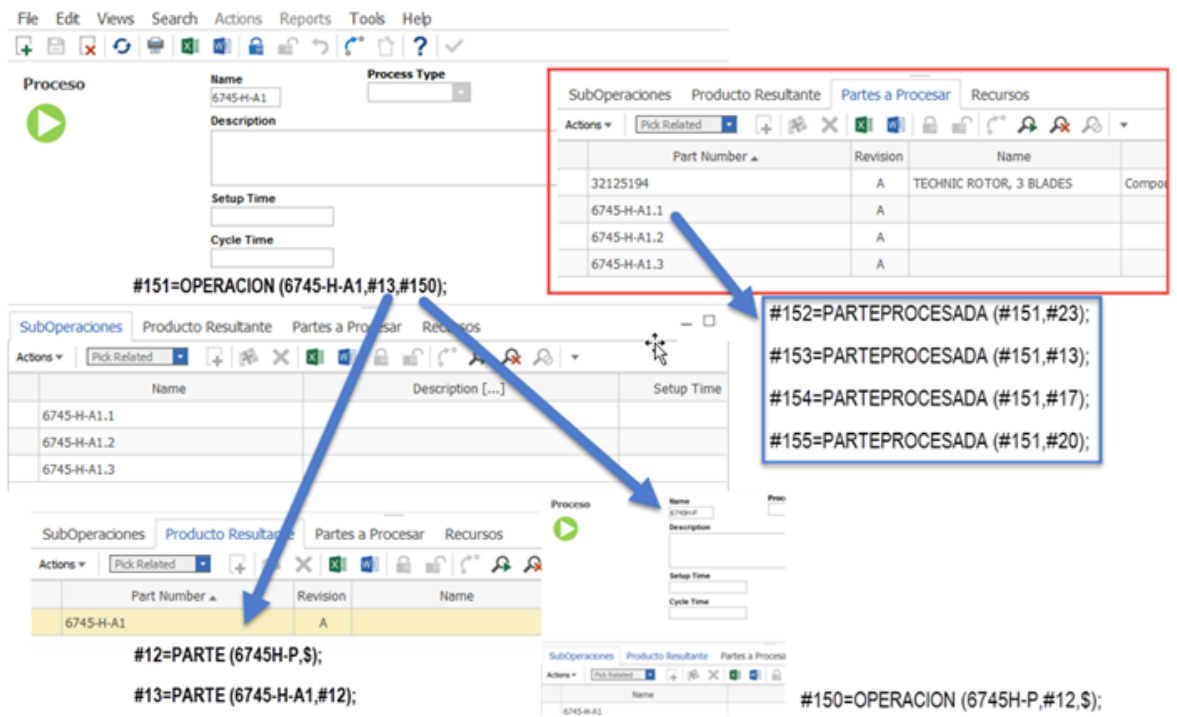

Fig. 7. ARAS Innovator, process plan interoperability. 


\section{Conclusions}

Interoperability among engineering software systems, mainly CAX and PLM, is one of the main concerns of the ISO TC184 SC4, which is in charge of developing standards such as the ISO 10303 STEP. The currently available data translators, implementing STEP application protocols, deal mainly with 3D geometric data, tolerancing and dimensioning data and basic management data. Those data are particularly relevant for a product DMU, when considering an industrial DMU (iDMU), and in particular, assembly processes, it seems to be a gap. This work shows a very basic study dealing with that gap and with its application in an aerospace context.

In particular, the outcomes of this work come in two ways. Firstly, with a development of a tool to map EXPRESS-G and UML class diagrams. Secondly, with the proposal of a basic iDMU data model used to implement a data exchange between CATIA/DELMIA V5 and ARAS Innovator. Industrialization data are created in the CATIA/DELMIA V5 software system; it is exported into an STEP file, and then imported into ARAS Innovator. The data exchange comprises iDMU management data. It is an initial work aiming to understand the development implications of this kind of information exchange in a PLM context.

\section{$7 \quad$ References}

1. Altfeld H.-H. (2010) Commercial Aircraft Projects: managing the development of highly complex products, Ashgate Pub. L., Farnham, England.

2. Mas, F., Menéndez, J. L., Oliva, M., Gómez, A., \& Ríos, J. (2013, July). Collaborative engineering paradigm applied to the aerospace industry. In IFIP International Conference on Product Lifecycle Management (pp. 675-684). Springer Berlin Heidelberg.

3. Mas, F., Menéndez, J. L., Oliva, M., Ríos, J., Gómez, A., \& Olmos, V. (2014, June). iDMU as the Collaborative Engineering engine: Research experiences in Airbus. In Engineering, Technology and Innovation (ICE), 2014 International ICE Conference on (pp. 17). IEEE.

4. Pardessus, T. (2001) The multi-site extended enterprise concept in the aeronautical industry. Air \& Space Europe, 3, 46-48.

5. Kern, V. M., \& Bøhn, J. H. (1995). STEP databases for product data exchange. In Proceedings of I International Congress of Industrial Engineering (Vol. 3, pp. 1337-1341).

6. Subrahmanian, E., Rachuri, S., Fenves, S. J., Foufou, S., \& Sriram, R. D. (2005). Product lifecycle management support: a challenge in supporting product design and manufacturing in a networked economy. International Journal of Product Lifecycle Management, 1(1), 4-25.

7. Rachuri, S., Subrahmanian, E., Bouras, A., Fenves, S. J., Foufou, S., \& Sriram, R. D. (2008). Information sharing and exchange in the context of product lifecycle management: Role of standards. Computer-Aided Design, 40(7), 789-800.

8. AeroSpace and Defence Strategic Standardization Group (ASD SSG) (2014) Through Life Cycle Interoperability: a critical strategic lever for competitiveness. (Available online at http://www.asd-ssg.org).

9. Van Ruijven, L. C. (2012). Ontology and model-based systems engineering. Procedia Computer Science, 8, 194-200. 
10. Mas, F (2014). Desarrollo de un sistema basado en el conocimiento para la definición de líneas de montaje aeronáuticas en la fase conceptual: Aplicación a una aeroestructura aeronáutica. . (Doctoral thesis, Universidad Politécnica de Madrid, Spain). Retrieved from http://oa.upm.es/28993/, 2014.

11. Mason H. (2002) 'ISO 10303 - STEP. A key standard for the global market', ISO Bulletin, January 2002, pp. 9-13.

12. ISO 10303-1:1994 (1994) 'Industrial automation systems and integration - Product data representation and exchange - Part 1: Overview and fundamental principles', ISO.

13. ISO 10303-21:1994 (1994) 'Industrial automation systems and integration - Product data representation and exchange - Part 21: Implementation methods: Clear text encoding of the exchange structure', ISO.

14. Arnold, F., and Podehl, G. (1998, June). Best of both worlds-a mapping from EXPRESS$\mathrm{G}$ to UML. In International Conference on the Unified Modeling Language (pp. 49-63). Springer Berlin Heidelberg.CSN EN 9300-003 (2012) 'Aerospace series - LOTAR - Long term archiving and retrieval of digital technical product documentation such as 3D, CAD and PDM data - Part 003: Fundamentals and concepts', CSN

15. Delaunay, J. Y. (2012) 'Long Term Archiving and Retrieval of PLM Information in the Aerospace and Defence Industries', ProSTEP iViP Symposium, May 2012.

16. Object Management Group. (2015) 'Reference Metamodel for the Express Information Modeling Language V1.1 http://www.omg.org/spec/EXPRESS/1.1/, (Last Access: 02/03/2017).

17. Florian A., Gerd P. Best of Both Worlds -A Mapping from EXPRESS-G to UML. International Conference on the Unified Modeling Language UML 1998: The Unified Modeling Language. «UML»'98: Beyond the Notation pp 49-63.

18. Aras Corportation. (2015) 'Making the Case for resilient PLM" http://www.aras.com/,. (Last Access: 02/03/2017)

19. Dassault Systemes. Delmia V5 Assembly. https://www.3ds.com/fileadmin/PRODUCTS/DELMIA/PDF/Brochures/delmia-dpmassembly.pdf/,. (Last Access: 02/03/2017) 